\title{
AUTONOMIA, COLABORAÇÃO, AUTORIA E DOCÊNCIA NA CIBERCULTURA - QUESTÕES SOB A ÓTICA DE FREIRE E BERNSTEIN
}

\section{AUTONOMY, COLLABORATION, AUTHORSHIP AND TEACHING IN CYBERCULTURE - ISSUES UNDER THE VIEW OF FREIRE AND BERNSTEIN}

\section{AUTONOMÍA, COLABORACIÓN, AUTORÍA Y ENSEÑANZA EN CIBERCULTURA: CUESTIONES DESDE LA VISTA DE FREIRE Y BERNSTEIN}

Clarisse de Mendonça e Almeida ${ }^{1}$ Vittorio Leandro Oliveira Lo Bianco ${ }^{2}$

\begin{abstract}
RESUMO
O presente trabalho articula-se com as obras de Freire (1996) e Bernstein (2000) para abordar os conceitos de autonomia, colaboração e autoria compreendendo-os como elementos fundamentais da cibercultura (SANTOS, 2019) para pensar caminhos para uma educação mais flexível e focada não apenas na atuação docente, mas também na participação do aluno. Para tanto, parte-se do debate sobre a formação continuada docente como questão central para o desenvolvimento de um profissional capaz de, criticamente, compreender e atuar frente aos desafios impostos pela cibercultura (SANTOS, 2019) no que se refere à autoria e à colaboração na produção do conhecimento. Em seguida, propõe-se a articular este pensar com a estruturação de processos de ensino menos estruturados na figura central do professor e mais na autonomia do docente (FREIRE, 1990) e na contribuição de todos os envolvidos como elemento de ruptura aos modelos hierárquicos de educação (BERSTEIN, 1990). Para tanto, pretende-se gerar a compreensão de que tais objetivos somente se alcançam ao construirmos a figura do docente como um ser investigativo (NÓVOA, 2017), dotado naturalmente de curiosidade epistemológica (FREIRE, 1990).
\end{abstract}

PALAVRAS-ChAVE: Cibercultura, Docência, Currículo, Formação continuada

\section{ABSTRACT}

The present work is articulated with the works of Freire (1996) and Bernstein (2000) to approach the concepts of autonomy, collaboration and authorship, understanding them as fundamental elements of cyberculture (SANTOS, 2019) to think about paths for a more flexible education and focused not only on teaching performance, but also on student participation. To this end, it starts from the debate on continuing teacher

Submetido em: 30/05/2021 - Aceito em: 29/08/2021 - Publicado em: 13/10/2021

\footnotetext{
${ }^{1}$ Doutorando em Políticas Públicas e Formação Humana (UERJ); Mestre em Educação (UniRio).

${ }^{2}$ Doutor em Educação pelo ProPEd/UERJ, Mestre em Políticas Públicas, Estratégias e Desenvolvimento pelo Instituto de Economia da UFRJ
} 
education as a central issue for the development of a professional capable of critically understanding and acting in the face of the challenges imposed by cyberculture (SANTOS, 2019) in regard to authorship and collaboration in the production of knowledge. Then, it is proposed to articulate this thinking with the structuring of less structured teaching processes in the central figure of the teacher and more in the autonomy of the teacher (FREIRE, 1990) and in the contribution of all involved as an element of rupture to the hierarchical models of education (BERSTEIN, 1990). To this end, it is intended to generate the understanding that such objectives are only achieved by building the figure of the teacher as an investigative being (NÓVOA, 2017), naturally endowed with epistemological curiosity (FREIRE, 1990).

KEYWORDS: Cyberculture, Teaching, Curriculum, Continuing education

\section{RESUMEN}

El presente trabajo se articula con los trabajos de Freire (1996) y Bernstein (2000) para abordar los conceptos de autonomía, colaboración y autoría, entendiéndolos como elementos fundamentales de la cibercultura (SANTOS, 2019) para pensar formas de una educación más flexible. y se centró no solo en el desempeño docente, sino también en la participación de los estudiantes. Para ello, se parte del debate sobre la formación continua del profesorado como eje central para el desarrollo de un profesional capaz de comprender y actuar críticamente ante los retos que impone la cibercultura (SANTOS, 2019) en materia de autoría y colaboración en la producción de conocimiento. Luego, se propone articular este pensamiento con la estructuración de procesos de enseñanza menos estructurados en la figura central del docente y más en la autonomía del docente (FREIRE, 1990) y en el aporte de todos los involucrados como elemento de ruptura a la los modelos jerárquicos de educación (BERSTEIN, 1990). Para ello, se pretende generar el entendimiento de que tales objetivos solo se logran construyendo la figura del docente como ser investigador (NÓVOA, 2017), naturalmente dotado de curiosidad epistemológica (FREIRE, 1990).

PALABRAS CLAVE: Cibercultura, Docencia, Currículum, Educación continua

\section{INTRODUÇÃO}

Atravessados pelos desafios advindos do cenário da cibercultura (SANTOS, 2019) e pelas tecnologias digitais que interferem no olhar sobre o mundo, sobre o outro e sobre o que os cercam, educadores enfrentam o desafio de discutir estratégias de reorganização e revisão de processos de ensino-aprendizagem, enraizadas há décadas. A incorporação de tecnologias digitais aos processos educacionais nas últimas décadas trouxe consigo a proposta de novos padrões de atuação para docentes e alunos. Novos desenhos metodológicos são propostos e construídos graças às interferências e às aderências tecnológicas e com foco principal na atuação colaborativa e na autoria de todos os envolvidos. $\mathrm{O}$ debate atual aponta ainda para a tendência de uma educação mais focada nos "entrelaçamentos" (NÓVOA, 2017) entre alunodocente e instituições de ensino-sociedade. Ou seja, em um ensino cuja palavra-chave, de acordo com Nóvoa (2017), seja a colaboração e o percurso integrado da educação.

Nesse contexto, o ser humano mantém laços estreitos com as tecnologias digitais. Mais que uma relação de proximidade, há um entrelaçamento e um novo arranjo temporal e espacial capaz de influenciar não apenas os processos comunicacionais mais evidentes, mas também de intervir em padrões sociais, culturais e educativos. Na perspectiva de Coll (2013), 
podemos descrever a realidade como um sistema aberto, um organismo vivo, nada inerte, que se reorganiza a todo o momento de acordo com influências internas e externas por meio de contribuições dos sujeitos envolvidos e construindo, assim, novas relações e teias de significados, com o apoio de ferramentas tecnológicas (COLL, 2013).

Motivados pela possibilidade de conexão permanente, os sujeitos se veem atraídos pela exploração e pela experimentação proporcionadas na interação com os diversos meios digitais. Configura-se, assim, a cibercultura, "como a cultura contemporânea que revoluciona a comunicação, a produção e circulação em rede de informações e conhecimentos na interface cidade-ciberespaço" (SANTOS, 2019, p. 21). É a cultura contemporânea estruturada pelas tecnologias digitais de onde emergem novos perfis cognitivos, com demandas próprias e traçando relações únicas e diferenciadas com os processos de ensino e aprendizagem (SANTOS, 2013).

Exige-se cada vez mais do docente ao inseri-lo assim em uma longa trajetória de formação continuada. No caso deste trabalho, ao invés de nos focarmos nos anos iniciais de formação, i.e., no "começo da construção do eu professor" (MARTINEZ et al., 2015, p.24), orientamonos para a compreensão da relação entre o saber teórico e o saber prático, assim como nos contributos advindos da própria sociedade e que permeiam toda a vida profissional. Somado a isso, há uma tendência em se valorizar a atuação do aluno como o ponto central do processo de ensino-aprendizagem. No entanto, novos desenhos metodológicos têm sido construídos graças às interferências e às aderências tecnológicas e que se apoiam na atuação colaborativa e na autoria compartilhada - elementos marcantes da contemporaneidade.

Este universo de interações e práticas junto às possibilidades digitais resvala para o campo educacional e consequentemente para a formação docente. Diversos atores sociais - mesmo distante geograficamente - tornam-se capazes de compartilhar projetos em comum, de modo simultâneo, focados na colaboração e não mais centrados na singularidade de uma pessoa, considerada a detentora do saber. Todos colaboram, todos se comunicam e todos aprendem. Os saberes circulam e se recombinam, de forma nômade, gerando uma combinação das diversas áreas do conhecimento, rompendo separações de papéis e atribuições préestabelecidas. Há espaço para expressões, trajetórias, escolhas e interesses únicos e pessoais. Isso, por si só, já poderia representar uma nova forma de organizar a informação, de aprender e produzir conhecimento. E esse é o ponto que, de fato, nos interessa discutir neste texto, gerar um entrelaçamento, mesmo que representando tempos históricos distintos, com a ótica de Paulo Freire para uma educação libertária e de Basil Bernstein no que se refere às relações de poder e hierarquia, vividas no campo educacional. Com especial atenção às questões que envolvem a autonomia, a colaboração e o currículo, o presente artigo traz como eixo central as obras desses dois autores, como os principais articuladores para os pontos apresentados, 
em diálogo com demais investigadores (SANTOS, 2019) e com as práticas educacionais emergentes e emergenciais possíveis na cibercultura.

A partir do cenário aqui descrito, o presente trabalho propõe um diálogo com Paulo Freire (1996), em sua obra Pedagogia da Autonomia (1996), especialmente no que tange à potencialidade de autoria e colaboração, experimentadas junto aos recursos advindos das tecnologias digitais. Reconhecemos, no entanto, que sua obra extrapola qualquer limitação de debate sobre as propostas de modelos de ensino para se situar naquilo que lhe é mais relevante: uma transformação social a partir da reorganização do pensamento educacional vigente.

Embora a obra de Freire se reporte a um tempo cronológico passado, acreditamos que a obra de Freire se entrelaça com as questões da atualidade ao problematizar a formação e a atuação docente como um diálogo com os diferentes aspectos da sociedade e ao pensar nos sujeitos como seres únicos e inacabados. Freire (1996) parte do conceito de autonomia para apresentar fatores que, na visão do autor, contribuem para o rompimento de um antagonismo limitador na relação aluno-professor. A afirmação do autor de que "nas condições de verdadeira aprendizagem os educandos vão se transformando em reais sujeitos da construção e da reconstrução do saber ensinado" (FREIRE, 1996, p.28) se aproxima da discussão contemporânea de defesa de um modelo de ensino que respeite os aspectos da atualidade, o tempo, a experiência, o momento e as intervenções de cada aprendiz ao longo do processo. Segundo o autor, para que haja resultados significativos, há de pensar em aprendizes e educadores instigadores, inquietos e criadores capazes, por exemplo, de pesquisar e incorporar aspectos da realidade às práticas pedagógicas.

Ao lidarmos com as questões da contemporaneidade na relação com as tecnologias digitais, nos remetemos ainda a Basil Bernstein (2000), representante da Nova Sociologia da Educação, para pensar se a configuração atual de sociedade minimizaria, ou não, as relações de poder vividas na educação e de hierarquia de saberes. Isso se daria porque diversos atores sociais - mesmo distantes geograficamente - tornam-se capazes de compartilhar projetos em comum, de modo simultâneo, focados na colaboração e não mais centrados na singularidade de uma pessoa, considerada a detentora do saber. Todos colaboram, todos se comunicam e todos aprendem. Os saberes circulam e se recombinam, de modo nômade e horizontalizado, em uma combinação de diversas áreas do conhecimento. Há espaço para expressões, trajetórias, escolhas e interesses únicos e pessoais. Tal entendimento, por si só, já poderia representar uma nova forma de organizar a informação, de aprender, produzir e disponibilizar conhecimento. 
A primeira parte deste trabalho reflete justamente acerca do reconhecimento de um modelo ainda vigente de ensino em que o professor assume o papel de transmissor de uma linguagem controlada e uniformada (BERNSTEIN, 2004, p.9) e de reprodutor de um conhecimento previamente definido. Uma possível ruptura desse modelo e a construção de novas propostas mais próximas às particularidades do contexto de cibercultura (SANTOS, 2019), no entanto, exigiriam autonomia por parte do docente e flexibilidade curricular. E representaria um esforço de engajamento às mudanças culturais, económicas e tecnológicas contemporâneas (BERNSTEIN, 2000). Ao invés da lógica de reprodução de um currículo top-down (LEITE \& FERNANDES, 2010) buscaria-se a construção de um modelo, organizado horizontalmente, que permitisse interferências e revisões a todo o momento. Isso implicaria na busca por propostas descentralizadas que emergem do contexto das escolas.

A segunda parte deste texto se propõe a buscar uma aproximação entre o tema do currículo flexível com a possibilidade de construção de um modelo de educação mais aberto a contributos e mais alinhado com as questões da contemporaneidade, especialmente no sentido de produção e compartilhamento de conhecimento. Sendo assim, focaremos nos contributos da obra de Bernstein (2000), na compreensão de que, ao darmos voz a novas possibilidades de autoria - impulsionadas pelo uso de tecnologias digitais - promovemos uma comunicação mais democrática, inclusiva e menos hierárquica.

A terceira parte nasce do entendimento de que tanto uma revisão de currículo e das relações de poder (BERNSTEIN, 2000) quanto a construção de modelos educacionais mais colaborativos somente são passíveis de concretude na medida em que se recomponha e se valorize a "dimensão intelectual e investigativa da docência" (NÓVOA, 2017, p.1108). Ou seja, em um ensino cuja palavra-chave, para Nóvoa (2017), seja a colaboração e o percurso integrado para a formação e que siga a tendência de uma educação mais focada nos "entrelaçamentos" (NÓVOA, 2017, p.1110) entre aluno-docente e instituições de ensinosociedade.

\section{DIÁLOGOS ENTRE CIBERCULTURA E DOCÊNCIA}

Compreendemos o ciberespaço como o ambiente virtual onde, a partir das interfaces digitais de comunicação síncronas e assíncronas, há a utilização de mídias diversas e de interações que proporcionam a coletivização dos saberes em rede. Ou seja, o fluxo de relações entre os seres humanos e as interfaces digitais oportuniza o compartilhamento de sentidos dentro do contexto infocomunicacional, estabelecendo diferentes sociabilidades (SANTOS, 2009). Trata-se, nas palavras de Santos (2013), "da cultura contemporânea estruturada pelo uso das tecnologias digitais em rede nas esferas do ciberespaço e das cidades”. Neste lugar, formam- 
se espaços multirreferenciais de aprendizagem (SANTOS, 2013) que contemplam e articulam diversos espaços, tempos, linguagens, tecnologias para além dos espaços legitimados pelo ensino formal e onde o aprender se dá pelo encontro com a diversidade e a pluralidade de enxertos e referências.

A noção de espaço de aprendizagem vai além dos limites do conceito de espaço/lugar. Novas relações com o saber vão se instituindo num processo híbrido entre o homem e máquina, tecendo teias complexas de relacionamentos com o mundo (SANTOS, 2002, p.121).

O conceito de cibercultura também é compartilhado por Lemos (2005). Para o autor, padrões, até então estruturados e enraizados, se quebram, formando uma série de fragmentos que se combinam e recombinam ao gosto do sujeito que é justamente quem conduz essa dinâmica no tempo e no momento que lhe convier. Na cibercultura planetária (LEMOS, 2015) estamos a falar de um cenário que carrega em si uma espontaneidade das relações que se formam pelas oportunidades vividas no mundo virtual de uma sociedade globalizada e em permanente movimento.

Nesse contexto da educação na cibercultura, podemos destacar o potencial do modelo de Educação Online, que não deve ser confundida nem com a estrutura da Educação a Distância e nem um desdobramento dela, sendo um fenômeno da cibercultura, praticada em rede (SANTOS, 2020). Deve-se diferencia-la, do mesmo modo, das práticas stuais do Ensino Remoto. A Educação Online envolve modos de ensino aprendizagem - ou atos de currículo (MACEDO, 2011) - mediados por interfaces digitais (PIMENTEL, 2018). Está diretamente inspiradas em nossas vivências online, remetendo à comunicação todos-todos a partir da liberação dos polos de emissão oportunizada pelo digital em rede. Transita por sistemas computacionais diversos, dialogando com a interatividade, a dialogia, a conectividade e a autoria (PIMENTEL, 2018).

$\mathrm{Na}$ Educação Online, os chamados ciberdocentes estimulam a produção dos estudantes como co-autores, dispertando a consciência sobre os percursos de aprendizagem. Para eles, a educação é uma "obra aberta, plástica, fluida, hipertextual e interativa" (SANTOS; SILVA, 2009, p. 275). Para isso, é importante considerarmos a docência artesanal, ou seja, aquela que permite que professores tenham autoria e criatividade no processo, utilizando as tecnologias educacionais para desorganizar, questionar ordens estabelecidas e "fomentar novas realidades a partir das palavras e dos gestos nascidos e, ao mesmo tempo, produtores do desejo - um desejo costurado coletivamente" (NOLASCO-SILVA, 2019).

Um dos desafios presentes na atualidade - e em discussão neste momento - trata justamente da formação do professor como um sujeito pesquisador, capaz de articular o saber com o cenário atual de hiperconexão por meio de tecnologias digitais e de acesso a uma infinidade 
de informações e experiências provenientes disso. É o momento, segundo Kenski (2015, p.426), de formar profissionais capazes de conviver com "espaços, seres, instituições e procedimentos fugazes, voláteis, que se alteram permanentemente" e a atuar "em um momento em constante (re)definição pessoal, cultural e social". Deste contexto, acredita-se, surgem novas formas de expressões, de produção e compartilhamento de conhecimento que precisam ser consideradas e discutidas também naquilo que envolve a formação de professores.

A percepção de que "como o estudante aprende influencia o papel que o professor assume em sala de aula bem como os métodos e as estratégias de ensino-aprendizagem adotados" (LEITE \& MONTEIRO, 2018, p.66) justifica em parte o presente trabalho. Tal justificativa se soma à discussão do currículo como mecanismo de poder (BERNSTEIN, 2000, 2004), da comunicação e da necessidade de construção de caminhos mais abertos e democráticos para a educação. Logo, o presente texto recorre a conceitos como autonomia e colaboração, considerados elementos marcantes da cibercultura (SANTOS, 2019), para se pensar caminhos para a construção de uma educação mais flexível e focada não apenas na atuação docente, mas também na participação de todos. Para tanto, parte-se do debate sobre a necessidade de uma maior flexibilidade curricular de modo a atender às especificidades e às configurações desta realidade marcamente tecnológica e conectada e que quebre com a dinâmica de distribuição de conteúdos prontos ao professor.

Estas ideias são articuladas com as que se referem a modelos de ensino menos estruturados na figura central do professor e mais apoiados no contributo de todos os envolvidos em uma tentativa de ruptura com modelos hierárquicos de educação (BERNSTEIN, 2000). Como ideia principal, pretende-se trazer ao debate que tais objetivos são favorecidos quando o docente adquire autonomia e estrutura a sua ação através de uma forte relação entre ensinoinvestigação (NÓVOA, 2017) movido de uma curiosidade epistemológica (FREIRE, 1990) e em uma ação de indissociabilidade entre o ensino, a aprendizagem e a investigação (LEITE, 2015).

A defesa de uma figura docente como investigador também se mostra frequente na fala de Freire (1996) ao destacar a postura de pesquisador como inerente à atuação do docente, fruto de uma eterna curiosidade natural. Para o autor, a proposta de uma ação mais crítica por parte do educador, movida por uma curiosidade epistemológica geraria uma ação crítica sobre a própria prática. Associado a isso, proporemos uma articulação com Leite (2015, p.120) ao a conceber "a investigação constitui um meio de uma aprendizagem que favorece a construção do conhecimento". 


\section{COLABORAÇÃO, AUTONOMIA, AUTORIA E QUESTÕES CURRICULARES}

Com a propagação do uso da internet e de tecnologias digitais, a informação e a capacidade de compartilhamento de mensagens se encontram no centro do processo. Uma das implicações desse cenário diz respeito à construção de novas formas de sociabilidade, de produção e de aquisição de informação e conhecimento. Cada indivíduo ganha maior autonomia e voz ao construir e reconstruir relações em uma espécie de ecossistema que se mantém vivo e dinâmico todo o tempo e que não para nunca (COLL, 2013). A todo o momento, se está aberto à recepção de novas informações que podem auxiliar na aquisição de conhecimento e de novos pontos de vista.

É, neste contexto, atravessados por tecnologias digitais que interferem no olhar sobre o mundo, sobre o outro e sobre o que os cercam, que educadores em todo o mundo (MARTINEZ et.al, 2015) enfrentam o desafio de discutir estratégias de reorganização e reconstrução de processos de ensino-aprendizagem enraizados há décadas. O lugar das tecnologias digitais nas agendas educativas, nos currículos e nas políticas de formação docente é tema recorrente de debate em todo o mundo (MARTINEZ et al., 2015, p.21). O desafio está posto: formar docentes capazes de atuar nessa realidade ao desenvolver nos alunos as competências e habilidades necessárias para lidar com as complexidades desse cenário.

Os debates atuais apontam para um entendimento de que a própria formação docente e os modelos de ensino predominantes já não se alinham plenamente à formatação de uma sociedade de sujeitos hiperconectados, protagonistas da própria experiência junto ao conhecimento, com amplo acesso à informação e ao outro, independentemente dos seus locais de origem. Neste espaço de co-habitação fulltime entre o ser humano e a máquina, entre o online e o offline, rediscute-se e redefine-se aos poucos um novo posicionamento da educação, do conhecimento e de atuação docente. E é justamente essa questão que nos leva a Bernstein (2000). Na medida em que ganhamos autonomia e espaço para colaboração, revemos temas como currículo, poder, acesso e organização do conhecimento.

Novos caminhos para a educação são pensados, movidos pelas experiências vividas junto aos aparatos digitais e pela urgência em se integrar à realidade de uma geração de indivíduos que já nasce conectada e atraída pela exploração e pela experimentação proporcionadas pelos meios tecnológicos. Tendo como foco a atuação do aluno como o ponto central do processo, desenhos metodológicos são construídos graças às interferências e às aderências tecnológicas e como um dos focos principais a atuação colaborativa e autônoma. 
A autonomia representa um componente típico desses sujeitos imersos na sociedade contemporânea e que se mostra evidente e com implicações nos processos educacionais. No momento atual, de integração com as tecnologias digitais, o próprio sujeito torna-se autor não apenas dos próprios discursos - a partir daquilo que acessa e compartilha -, mas também de sua trajetória. É essa autonomia, discutida também por Freire (1996), que se encontra em evidência hoje, como capaz de levar - não apenas o aluno, mas também o docente - a se reconstruir a todo o momento e a conduzir essa trajetória de aquisição e construção do conhecimento.

No momento atual, de integração com a tecnologia, o próprio sujeito escolhe aquilo que lhe interessa acessar e é ele quem determina o momento em que começa e termina as suas interações assumindo, assim, a condução da sua própria trajetória. Isso lhe concede um grau de empoderamento e o coloca na figura de protagonista daquilo que acessa e da forma como interage com os demais indivíduos. Não se espera por nada, já que os anseios são atendidos no próximo clique. Como os feedbacks são imediatos, caso não se seja plenamente atendido, buscam-se novas respostas em outro site. E isso se reflete no próprio ato de estudar já que o acesso a materiais educacionais é amplo e aberto e se encontra ao alcance de uma busca simples na internet sem haver, sequer, a necessidade de locomoção. É essa autonomia, anteriormente citada e prevista por Freire (1996), que se encontra em evidência hoje, como capaz de levar o sujeito a se reconstruir a todo o momento e a conduzir essa trajetória de aquisição do conhecimento. Para Freire (1996), o processo de aprendizagem contínuo do docente surge do próprio reconhecimento de que somos sujeitos inacabados, conscientes dessa inconclusão e, portanto, movidos por uma curiosidade que nos guia no sentido de aprender mais e sempre.

Discutir a educação sob essa perspectiva nos permite uma aproximação com o pensamento de Bernstein (2000). Pensar propostas de construção colaborativa de conhecimento e de atuação autônoma dos envolvidos, suportadas por tecnologias digitais, exige um direcionamento e um aprofundamento acerca do tema das políticas curriculares e das relações de poder presentes no campo educacional. A construção de modelos menos rígidos e mais dinâmicos englobaria contributos de todos os envolvidos se mostrando como um caminho viável para a redução (ou ruptura) da linguagem controlada e uniformada da educação (BERNSTEIN, 2000). Diante de múltiplos cenários culturais advindos dessas participações estaríamos a construir espaços de troca mais democráticos. Estamos a falar de espaços que respeitam e aceitam a diversidade de seus membros dando-lhes voz e representatividade transferindo o poder da comunicação do professor para todos.

Estamos a construir um debate que se propõe romper com o papel do professor como mero transmissor de uma linguagem controlada e uniforme (BERNSTEIN, 2000, p.9) e de 
reprodutor de um conhecimento previamente definido. Há abertura não apenas para a junção e mescla de saberes - distantes e distintos - como também para os desdobramentos a partir da contribuição de todos. Uma distribuição mais colaborativa do conhecimento, com um emaranhado de sujeitos contribuindo simultaneamente se articula ainda com a proposta de uma educação de cunho libertário abandonando uma possível abordagem bancária e domesticada (FREIRE, 1987). Ou na linha de Bernstein (2000), representaria, entre outros pontos, a discussão sobre a recontextualização do conhecimento deslocando-o das mãos de poucos cujo poder possuem para tanto, para todos de modo mais igualitário.

A proposta de maior incorporação daquilo que as tecnologias digitais oferecem poderia contribuir para uma maior integração de saberes e conhecimentos fazendo-nos repensar as fronteiras hierárquicas entre as disciplinas (BERNSTEIN, 2004). O cenário de hiperconectividade e a formação de redes fomentam não apenas a troca e a autoria, mas também gera uma nova organização do conteúdo. Deixam-se de lado, posições hierárquicas e estatísticas para dar vez à formação de associações, teias e conexões, alimentada colaborativamente entre as partes envolvidas, a partir mais de interesses em comum do que proximidade física. Os conteúdos deixam o enquadramento rígido e a classificação hierárquica indicada nos currículos. Para Bernstein (2000), essa classificação e organização do conhecimento não se encontrariam abertas a diálogos, seriam rígidas e disfarçariam relações de poder.

Assim como Bernstein (2000), Young (2010), também parte integrante do movimento da Nova Sociologia da Educação (NSE), propõe uma nova forma de se olhar o currículo sob a perspectiva de um instrumento construído a partir da expressão de grupos e não apenas de um grupo com poder para tal atribuição. Esse grupo define o que deve ser ensinado e a quem se destina o conhecimento. Há uma tendência clara entre os autores a se olhar o currículo sob um viés crítico e problematizador, político e nada neutro. Ambos os autores convergem para o entendimento do currículo como expressão de poder, silenciada, mas que precisa ser evidenciada e problematizada. E, trazendo para o contexto atual, possa dialogar com as tecnologias digitais de modo a gerar expressões diversificadas, democráticas e inclusivas.

O próprio saber que advém do aluno e é oriundo da experiência dele próprio com a comunidade e com o cotidiano (FREIRE, 1996) pode ser incorporado e reconhecido como legítimo, trazendo contributos significativos. Reconhece-se ainda que há ainda o saber que provém do docente. Esse saber - que é único e particular a cada sujeito - carrega em si um caráter plural, heterogêneo reunindo conhecimentos provenientes de diversas fontes e naturezas sendo adquirido no contexto da vida cotidiana (TARDIF, 2012). É compreendido como aquele que não provém de uma fonte única, mas de múltiplas fontes formadoras. E não carrega em si a legitimidades das instituições formais. Há, assim, uma valorização da 
pluralidade e heterogeneidade de ideias, experiências e iniciativas que precisam ser valorizadas e incentivadas como parte da estratégia de motivação e renovação das práticas.

Bernstein (2000) e Young (2010) reforçam o posicionamento de que a distinção entre o conhecimento oficial e aquele adquirido no cotidiano acaba por legitimar determinados grupos no poder assim como seus interesses. E que além do conhecimento especializado, deve-se abrir espaço para a compreensão do mundo ao problematizar as práticas da sociedade e as experiências vividas. Seria justamente o conhecimento oriundo de múltiplas fontes, alimentado por mecanismos de colaboração e autonomia e suportado por tecnologias digitais, que se mostraria distinto do "conhecimento oficial elaborado e distribuído nas instituições educacionais" (BERNSTEIN, 2004, p.67). E, neste sentido, uma reforma curricular surge a partir das exigências de "engajamento nas mudanças culturais, econômicas e tecnológicas contemporâneas" (BERNSTEIN, 1990, p.67). Ou nas palavras de Monteiro (2011):

Neste contexto, já não faz sentido o determinismo curricular a priori das relações interpessoais, mas um currículo dinâmico, flexível, adaptado às exigências socioculturais, discutido, orientado para uma realidade prática e onde todos os intervenientes têm uma palavra a dizer e onde as tecnologias educativas têm um importante papel no que diz respeito à possibilidade de partilha num ambiente interactivo de comunicação sem limitações de tempo ou de espaço (MONTEIRO, 2011, p.92).

Ao se trabalhar a partir da perspectiva de um currículo pré-determinado, entregue como um pacote pronto, sem espaço para alterações ou acréscimos, não damos ao docente e nem aos alunos a autonomia possível, potencializada pelas ferramentas digitais. O professor, assim, segue como um ser passivo, de receptor e emissor de conteúdos que lhes são entregues. Deixamos de inseri-lo no espaço do coletivo, mantendo-o no isolamento do espaço de reprodução de conteúdos previamente selecionados e sem abertura para reflexões e problematizações sobre o que é transmitido. Ou seja, não lhe damos a chance de se assumir como figura ativa como "agente construtores de um currículo" (LEITE \& PACHECO, 20008, p.105). E não damos ao aluno a possibilidade de agir como "sujeitos capazes de gerir o próprio saber" e "contribuindo para o conhecimento da diversidade" (LEITE \& PACHECO, p.105). Para Libâneo (2014), atitudes e práticas interdisciplinares não condizem com a rigidez dos currículos e não permitem ao professor transitar entre as fronteiras disciplinares.

Ao tratarmos da flexibilidade do currículo e da autonomia para o professor geri-lo, rompe-se naturalmente com essa forma de controle social dita por Bernstein (2000). Seguindo a lógica do autor, uma distribuição do conhecimento não se daria por meio do compartilhamento de conteúdos pré-determinados em um pacote elaborado por aqueles cujo poder lhes foi atribuído. E sim, pela distribuição daquilo que cada um considerar relevante na interação com os demais e se estendendo ao saber do cotidiano. Abre-se caminho para a possibilidade de 
poder intervir, de atuar junto aos outros, sem a carga hierárquica típica do momento (BERNSTEIN, 2000), com flexibilidade e independência.

Neste entendimento, a aquisição do conhecimento deixa de ser uma sequência de atividades previstas e inflexíveis para dar vez a uma dinâmica de troca mútua contextualizada e problematizadora. Os professores deixariam de atuar como reprodutores de um currículo que lhes foi entregue pronto para agirem como agentes colaborativos e autônomos nesse processo e permitindo-lhes construir novas versões sobre o mesmo. E os alunos, ao invés de serem receptores do conhecimento, o ajudam a construir a partir das trajetórias individuais e daquilo que considerarem como relevante.

Esta maior autonomia e responsabilidade atribuídas aos professores nas decisões curriculares coloca-os perante novos desafios e novos dilemas, tendo em conta, por um lado, as múltiplas esferas em que repartem as atividades que têm de cumprir e, por outro, as exigências com a qualidade da educação a instituir (LEITE \& FERNANDES, 2010, p.199).

Essa perspectiva, como se vê, não se reduz à aquisição do conteúdo pré-estabelecido e planejado anteriormente pelas instituições formais de ensino e pelos órgãos oficiais. Ao contrário, propõe-se o trabalho com projetos de "mão dupla" possíveis de promover um maior engajamento e colaboração por parte dos envolvidos. Permite-se a abertura para intervenções tanto do aluno quanto do professor, reescrevendo uma trajetória que, por vezes, como já dito, chega a ser personalizada, mas não menos relevante, sob a dinâmica em rede.

O aluno aprende com o professor e este aprende com o aluno. E, neste sentido, as tecnologias digitais contribuem promovendo espaços de interação adequados para que haja a comunhão e a construção de um conhecimento gerado pela contribuição de todos mesmo que tenham seguido trajetórias diversas ou estejam em espaços distintos. Os alunos, ao terem maior possibilidade de atuação, se sentem "donos" do seu próprio progresso. O espaço da sala de aula torna-se o momento a reflexão e da prática de forma colaborativa já que o estudo do conteúdo pode, até mesmo, ser feito previamente.

\section{PROFESSOR COMO AGENTE INFLUENCIADOR DE MUDANÇAS}

A formação docente, historicamente marcada pela disciplinaridade e pela divisão e estruturação de conteúdos, pode representar um dos entraves para se readequar a formação docente à realidade contemporânea (MASETTO, 2018). O docente, não apenas nos anos iniciais de formação, mas de modo continuado, é orientado para lecionar uma determinada disciplina. Essa organização disciplinar, para Libâneo (2014), lidaria com o conhecimento de modo estanque, fragmentada impondo limites para a compreensão da complexidade do mundo. 
A classificação e a fronteira (BERNSTEIN, 2000) rigidamente marcadas entre as disciplinas talvez já não se alinhem a um cenário de múltiplas fontes de informação e experiência. Se anteriormente, ao docente cabia-lhe compreender e transpor para os alunos os conteúdos limitados ao que o currículo de uma determinada disciplina exigia, hoje, na perspectiva de modelos mais abertos e flexíveis, pode-se ampliar esse olhar e essa atuação. Ou, pela lógica de Coll (2013), como um sistema aberto, um organismo vivo, nada inerte, que se reorganiza a todo o momento de acordo com influências internas e externas por meio de contribuições dos sujeitos envolvidos e construindo, assim, novas relações e teias de significados, com o apoio de ferramentas tecnológicas.

Para Masetto (2018), o foco dos programas de formação de professor deve ser a aprendizagem dos alunos e não apenas as formas de transmissão de conteúdo. Segundo ele, apenas mudar a perspectiva de se enxergar o trabalho docente já geraria modificações nas práticas pedagógicas. $\mathrm{O}$ autor transpõe para a formação do professor o conceito de educação aberta e em rede de modo a tornar o próprio aluno o protagonista do seu aprendizado e, por isso mesmo, geram perspectivas, experiências e visões diferentes sobre um mesmo fato - o que por si só já seria inovador.

Caminhos que partem de contextos diferentes, caminham paralelos, se encontram e se entrecruzam em processos semelhantes e em buscas conjuntas, integram-se em ações grupais e prosseguem juntos ou em caminhos diversos em direção aos próprios objetivos de formação profissional do século XXI (MASETTO, 2018).

Não bastaria a esse docente ser o detentor de determinado conhecimento. É preciso que se tenha a visão do todo, da complexidade do saber e não somente de partes fragmentadas que não se interpõem ou cruzam entre si. Seguindo a mesma linha, Leite (2015) afirma que "é difícil admitir-se a docência sem que ela esteja associada aos últimos conhecimentos produzidos e que correspondem a uma contínua amplitude das fronteiras onde se situam" (LEITE, 2015, p.119). Ao mantermos a divisão e a classificação dos saberes - e a formação de professores seguindo o mesmo princípio -, limitamos e restringimos à prática docente a um "controle que regula e legitima a comunicação nas relações pedagógicas" (BERNSTEIN, 2004, p.8). E corremos o risco de deixar de fora o "conhecimento poderoso" (YOUNG, 2010), aquele que, de fato, contribui para o entendimento da complexidade da sociedade, dos fenômenos naturais e sociais.

A perspectiva de uma docência mais aberta, estruturada em rede, poderia representar uma quebra com as relações dominantes de poder e de controle nas formas de comunicação presentes na escola (BERNSTEIN, 1990). A lógica é que se pensarmos na possibilidade de formar docentes capazes de atuar em rede, teremos que trabalhar com a possibilidade de todos colaborarem sem divisões de classe ou poder. E pode funcionar como um importante 
instrumento de discussão de poder, de partilha, "assentes em princípios de uma comunicação democrática” (MONTEIRO, 2011, p.84).

A hiperconectividade e a organização em rede fomentariam não apenas a troca e a autoria, mas também gera uma nova organização do conteúdo. Deixam-se de lado posições hierárquicas, de poder e o currículo pré-determinado (BERNSTEIN, 2000) para dar vez à formação de associações, teias e conexões. São esquemas alimentados colaborativamente entre as partes envolvidas, formando nós agrupados a partir de interesses. Sendo assim:

Ao dialogarmos na rede, ao habitarmos a rede, estamos adquirindo uma nova forma de organização das informações, de nos relacionarmos perante os problemas e também uma nova forma de diálogo com diversos atores e, sobretudo um novo tipo de inteligência e de conhecimento. (LEMOS e FELICE, 2014, p.12)

Para avançar no sentido de uma formação docente mais significativa e alinhada com a discussão aqui apresentada, precisamos nos reconhecer primeiramente como seres únicos e inacabados, que se formam ao longo da vida (FREIRE, 1996). A afirmação do autor de que "nas condições de verdadeira aprendizagem os educandos vão se transformando em reais sujeitos da construção e da reconstrução do saber ensinado" (FREIRE, 1996, p.28) se aproxima perfeitamente à discussão contemporânea de defesa de um modelo de ensino que respeite os aspectos da atualidade, o tempo, a experiência, o momento e as intervenções de cada aprendiz ao longo do processo. E ao professor, caberia justamente "ajustar sua didática às novas realidades da sociedade, do conhecimento, do aluno" (LIBÂNEO, 2014, p.13) tendo em vista uma educação emancipatória e crítica. Para o autor, "é necessário também o intercâmbio entre formação inicial e formação continuada, de maneira que a formação dos futuros professores se nutra das demandas da prática" (LIBÂNEO, 2014, p.13).

Para Freire (1996), o ato de ensinar não se esgota na mera explanação dos conteúdos por parte do professor. Segundo o autor, para que haja resultados significativos, há de pensar em aprendizes e educadores instigadores, inquietos e criadores capazes, por exemplo, de pesquisar e incorporar aspectos da realidade às práticas pedagógicas. É preciso formar um educador que veja o "mundo como um objeto de pensamento e não como um lugar de experiência" (YOUNG, 2010, p. 616). E, de acordo com Bernstein (2000), rever esse olhar significaria ressignificar processos de modo a torná-los mais democráticos.

No pensamento de Freire (1996), um docente que atue como mero memorizador e transferidor de conteúdo, não se mostra capaz de articulador esse conhecimento com a realidade mais próxima a sua volta e é justamente o caminho inverso que, assim como o autor, defendemos aqui: o professor como um sujeito capaz de articular o saber com o cenário atual de hiperconexão por meio de tecnologias digitais e de acesso a uma infinidade de informações e experiências provenientes disso. 
Superada a visão tecnicista de incorporação das tecnologias digitais às práticas, como sugerem grande parte das políticas públicas com foco na formação docente (NÓVOA, 2017), chegamos a debate e de transposição para a formação docente de uma base de sustentação que descentralize a discussão do uso da tecnologia para identificar que "propósito pedagógico se pretende atingir e quais competências se quer desenvolver" (DIAS-TRINDADE, 2018, p.100). Afinal, não basta apenas o acesso aos aparatos a essas ferramentas. O modo como se vivencia essa experiência e como ela é transposta para os alunos talvez represente o ponto mais importante na relação do docente com essa cultura digital e com a futura integração das TICs nas suas práticas. Neste momento, devemos deixar de lado o viés meramente instrumental dessas ferramentas para se repensar o que se espera do aluno e do professor na contemporaneidade. Mais do que a utilização das tecnologias apenas pela sua utilização, a discussão tem de se centrar no seu impacto pedagógico no que se depreende como "bom" ensino e como fatores de promoção da qualidade na aprendizagem (DIAS-TRINDADE, 2018, p.100). Ou como acreditamos aqui, trata-se de elaborar estratégias significativas para o aluno e não apenas instrumental.

Uma proposta de reflexão ou de qualquer mudança no campo educacional somente é possível de implementação se contar com a adesão e a participação dos docentes. Tal constatação não se mostra recente, mas se reafirma e se reforça quando partimos de um papel de reprodutor de conteúdos para uma postura ativa e autônoma de participação e de colaboração. Para Leite \& Fernandes (2010, p.100), tal postura envolve mais do que adesão "o desenvolvimento de competências e habilidades que permitam aos docentes, de modo significativo às partes, partilhar o ato de ensinar e de fazer aprender".

É evidente, para que as escolas sejam lugares de decisão curricular, é necessário que sejam reconhecidas como espaços de autonomia pedagógica e de gestão do currículo, mas também é necessário que os professores/educadores queiram e saibam assumir profissionalmente essa autonomia (LEITE, 2006, p.75).

Estamos a falar de um profissional disposto a provocar rupturas em tradições construídas há tempos. A esse docente, caberia, entre outras atribuições, a de se assumir como um eterno pesquisador e curioso não apenas com relação ao conteúdo proferido nas aulas, mas também atento ao comportamento e à voz do grupo. Trata-se de um professor que considera aquilo que lhe é ofertado no momento da formação inicial, mas que também experimenta outros espaços menos tradicionais e confinados.

Essa proposta de atuação docente provoca tensões na medida em que se exige novas atribuições e um novo tipo de engajamento por parte do professor o que nos leva a discutir se, de fato, apenas a inclusão de tecnologias digitais ao longo da sua trajetória acadêmica seria 
suficiente para formar profissionais capazes de atuar nessa sociedade e de se aproximar da realidade dos alunos.

Os professores têm de saber gerir essas diferentes esferas de acção de modo a que, por um lado, não se sintam desqualificados profissionalmente e, por outro, não deixem passar para a imagem pública uma imagem de si como maus profissionais (LEITE \& FERNANDES, p.199, 2010).

O foco é pensar a docência como algo que se associa aos últimos conhecimentos em uma relação de contínua amplitude das fronteiras onde se situa em uma relação indissolúvel entre ensino-aprendizagem-investigação (LEITE, 2015). Tal questionamento se mostra relevante para se repensar o ensino não mais como um espaço de memorização e repetição, mas sim a partir de uma perspectiva mais focada na colaboração e na autonomia. Ou, na perspectiva de Bernstein (2000) como um espaço de partilha e de comunicação e atuação democráticas. Neste sentido, Young (2010) reforça a importância da universidade se firmar como espaço de seleção, pesquisa e de experimentação de novos conhecimentos a serem compartilhados na escola.

A reflexão sobre o lugar das tecnologias digitais na formação docente e nos processos educacionais nos leva a uma aproximação com a teoria dos dispositivos pedagógicos, elaborada por Bernstein (2000). Segundo o autor, é o dispositivo pedagógico que fornece a "gramática intrínseca do discurso pedagógico" (p. 254). Bernstein (2000) aponta três principais pontos do dispositivo pedagógico: produção, recontextualização e reprodução. Organizado de modo hierárquico, as três partes se conectam e se complementam. A produção do conhecimento tem sua a origem nas instituições de ensino superior e organizações de pesquisa. A recontextualização do conhecimento acontece no âmbito do Estado e das autoridades, periódicos do campo educacional e nas instituições formadora de professores. Já a reprodução se dá no interior das instituições de ensino nos mais diversos níveis.

Se pensarmos na perspectiva de uma educação mais aberta, em rede, desestruturamos esse ciclo e a origem, a recontextualização e a reprodução passam a se dar na relação entre os que ali participam - desde que sejamos capazes de formar professores que reconheçam as possibilidades de tal proposta e se vejam engajados à adesão. Um dos pontos em discussão nesse momento trata da adequação dessa formação de modo a atender e acolher esse aluno que chega com novas competências e habilidades oriundas de um contexto de proximidade e entrelaçamento com as tecnologias digitais.

Limitar a atuação docente ao papel de um sujeito meramente memorizador e transferidor de conteúdo, não articula esse conhecimento com a realidade mais próxima a sua volta. $\mathrm{O}$ momento é de ver o professor como um sujeito pesquisador, capaz de articular o saber com o cenário atual de hiperconexão por meio de tecnologias digitais e de acesso a uma infinidade 
de informações e experiências provenientes disso (FREIRE, 1996). Se o próprio docente não desenvolve suas próprias competências do saber, não será capaz de ajudar os alunos nessa compreensão do mundo (LIBÂNEO, 2014). E, portanto, permanecerão sujeitos a aprender do modo que lhes é imposto - hierárquico e de acordo com critérios e interesses de um grupo (BERNSTEIN, 2000).

Para Freire (1996), um docente que atue como mero memorizador e transferidor de conteúdo, não se mostra capaz de articulador esse conhecimento com a realidade mais próxima a sua volta e é justamente o caminho inverso que, assim como o autor, defendemos aqui: o professor como um sujeito capaz de articular o saber com o cenário atual de hiperconexão por meio de tecnologias digitais e de acesso a uma infinidade de informações e experiências provenientes disso.

Nas condições de verdadeira aprendizagem, os educandos vão se transformando em reais sujeitos da construção e da reconstrução do saber ensinado, ao lado do educador, igualmente sujeito do processo. Só assim, podemos falar realmente de saber ensinado, em que o objeto é apreendido na sua razão de ser e, portanto apreendido pelos educandos (FREIRE, 1996, P.28).

Para que haja resultados significativos, há de pensar em aprendizes e educadores instigadores, inquietos e criadores capazes, por exemplo, de pesquisar e incorporar aspectos da realidade às práticas pedagógicas. E mais ainda de valorizar a capacidade cognitiva daquilo que os alunos trazem para a escola (LIBÂNEO, 2014).

O que está em questão, portanto, é uma formação que ajude o aluno a transformar-se num sujeito pensante, de modo que aprenda a utilizar seu potencial de pensamento por meio de meios cognitivos de construção e reconstrução de conceitos, habilidades, atitudes e valores (LIBÂNEO, 2014, p.112)

Freire (1996) destaca ainda a postura de pesquisador que deveria ser inerente à atuação do docente, fruto de uma eterna curiosidade natural, extrapolando aquilo que o senso comum apresenta pronto a ele. Essa eterna curiosidade, nada ingênua, é parte integrante de um fenômeno vital que deveria também atingir aos educandos e geraria um compromisso de ambas as partes com a formação de uma consciência crítica - que não se dá naturalmente - e que se alinha, acreditamos, com a necessidade de se gerar uma visão mais reflexiva sobre o uso das tecnologias digitais por meio da própria inserção dessas ferramentas no processo de ensino-aprendizagem.

Há de se gerar um questionamento da própria prática, como um movimento entre o fazer e o pensar. E ao negarmos tal reflexão, correríamos o risco de formar profissionais alienados, detentores de um saber mais ingênuo, desconectado da realidade do próprio docente e do aluno (Freire, 1996). Neste viés, é que compreendemos que trazer à tona a discussão acerca da formação docente no entrelaçamento com as tecnologias digitais mostra-se vital para o 
entendimento de uma realidade que, como dito até aqui, não pode ser reconhecida de forma desconectada à educação.

\section{CONSIDERAÇÕES FINAIS}

Pensar e implementar propostas de modelos educacionais mais abertos, flexíveis e dinâmicos, como debatemos até o momento, vai além de instrumentalizar e munir as instituições de ensino e os docentes de acesso a tecnologias digitais. Estamos a falar de um processo que extrapola os limites impostos pelos currículos pré-definidos e saberes fragmentados (BERNSTEIN, 2000). Mas que somente se vê como viável se os docentes assumirem uma postura ativa, munidos de uma eterna curiosidade epistemológica (FREIRE, 1996) e sendo capazes de se alinhar às aspirações dos aprendizes.

A formação do professor, nesse cenário, possui um papel fundamental não apenas para uma nova compreensão do fazer docente, mas também para o entendimento de que o saber se constrói na interseção com a sala de aula com sujeitos e elementos externos ao currículo, na relação com o outro e com aquilo que não está pré-estabelecido. E que, ao se pensar dessa forma, damos espaço para uma comunicação mais colaborativa e democrática (BERNSTEIN, 2004).

Como aqui debatemos, é fundamental a formação continuada de docentes que sejam capazes de na interface com os alunos co-criarem novas percepções de mundo. Novos hábitos e padrões afetam os sujeitos, independente da idade de cada um deles, e neste sentido, a educação tem seu papel fundamental de promover a cidadania e a inclusão dos indivíduos nesta realidade, dando a eles o poder de exercerem o protagonismo típico do momento. A partir da potência das mídias interativas o processo de ensinoaprendizagem passa a permitir o encontro em novos arranjos espaçotemporais. É fundamental compreender que ocorre na cibercultura o giro comunicativo oportunizado pelo digital em rede, tendo na educação online um contraponto potente à educação bancária.

\section{REFERÊNCIAS}

BERNSTEIN, Basil. Pedagogy, symbolic control, and identity. Rowman \& Littlefield Publishers, 2000.

BERNSTEIN, Basil. The structuring of pedagogic discourse. Routledge, 2004. 
DI FELICE, Massimo; LEMOS, Ronaldo. A vida em rede. 2014.

DOS SANTOS, Adriana Cavalcanty; LEITE, Carlinda. Professor agente de decisão curricular: uma scriptura em Portugal. Magis, Revista Internacional de Investigación en Educación, v. 13, p. 1-21, 2020.

COLL, César. El currículo escolar en el marco de la nueva ecología del aprendizaje. Aula de Innovación Educativa, 2013, num. 219, p. 31-36, 2013.

DIAS-TRINDADE, Sara; MOREIRA, José António; NUNES, Catarina S. Escala de autoavaliação de competências digitais de professores. Procedimentos de construção e validação. Texto Livre: Linguagem e Tecnologia, v. 12, n. 2, p. 152-171, 2019..

FREIRE, Paulo. Pedagogia do oprimido. Rio de Janeiro: Paz e terra, 1987.

FREIRE, Paulo. Pedagogia da autonomia: saberes necessários à prática educativa. Rio de Janeiro: Paz e terra, 1996.

HARGREAVES, Andy. O Ensino na Sociedade do Conhecimento: a educação na era da insegurança. Porto: Porto Editora, 2003.

KENSKI, Vani Moreira. A urgência de propostas inovadoras para a formação de professores para todos os níveis de ensino. Revista Diálogo Educacional, v. 15, n. 45, p. 423-441, 2015.

LEITE, C. Políticas de currículo em Portugal e (im) possibilidades da escola se assumir como uma instituição curricularmente inteligente, 2006.

LEITE, Carlinda; PACHECO, Natércia. Os dispositivos pedagógicos na educação inter/multicultural. 2008.

LEITE, Carlinda; FERNANDES, Preciosa. Desafios aos professores na construção de mudanças educacionais e curriculares: que possibilidades e que constrangimentos?. Educação, v. 33, n. 3, 2010.

LEITE, C. A indissociabilidade ensino-aprendizagem-investigação: Contributos para uma reflexão. In: Libro de actas: VIII Congreso Iberoamericano de docencia universitaria y de nivel superior. Rosario, Humanidades y Artes Ediciones. 2015. p. 119-129.

Lemos, A. (2005). Ciber-cultura-remix.

LIBÂNEO, José Carlos. Adeus professor, adeus professora?. Cortez Editora, 2014.

MARTINEZ, Rosana; LEITE, Carlinda; MONTEIRO, Angélica. Os desafios das TIC para a formação inicial de professores: uma análise da agenda internacional e suas influências 
nas políticas portuguesas $=$ The ICT challenges on initial teacher education: an analysis of the international agenda and its influence on portuguese policies. 2015.

MASETTO, Marcos T. Trilhas abertas na universidade: inovação curricular, práticas pedagógicas e formação de professores. Summus Editorial, 2018.

MONTEIRO, Angélica Maria Reis. O currículo e a prática pedagógica com recurso ao blearning no ensino superior. 2011.

NOLASCO-SILVA, Leonardo. Tecnodocências: a sala de aula e a invenção de mundos. Salvador: Devires, 2019.

NÓVOA, António. Firmar a posição como professor, afirmar a profissão docente. Cadernos de pesquisa, v. 47, n. 166, p. 1106-1133, 2017.

SANTOS, Rosemary Santos; SANTOS, Edméa Oliveira. Cibercultura: redes educativas e práticas cotidianas. Revista Eletrônica Pesquiseduca, v. 4, n. 7, p. 159-183, 2012.

SANTOS, Edméa. Educação online para além da EAD: um fenômeno da cibercultura. Actas do X Congresso Internacional Galego-Português de Psicopedagogia. Braga: Universidade do Minho, 2009. Disponível em: < https://www.educacion.udc.es/grupos/gipdae/documentos/congreso/xcongreso/pdfs/t12/t12c4 27.pdf>. Acesso em: 24/05/2021.

SANTOS, Edméa. Educação online para além da EAD: um fenômeno da cibercultura. Educação Online: cenário, formação e questões didático-metodológicas. Rio de Janeiro: Wak Editora, 2010.

SANTOS, Edméa. Pesquisa-formação na cibercultura. Teresina: EDUFPI, 2019.

TARDIF, M. Saberes docentes e formação profissional. Editora Vozes Limitada, 2012.

YOUNG, Michael. Conhecimento e currículo: do socioconstrutivismo ao realismo social na sociologia da educção. Porto editora, 2010.

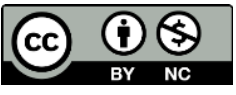

Este é um artigo de acesso aberto distribuído sob os termos da Licença Creative Commons Atribuição Não Comercial-Compartilha Igual (CC BYNC- 4.0), que permite uso, distribuição e reprodução para fins não comerciais, com a citação dos autores e da fonte original e sob a mesma licença. 